Tropical Journal of Pharmaceutical Research October 2019; 18 (10): 2025-2030

ISSN: $1596-5996$ (print); 1596-9827 (electronic)

(C) Pharmacotherapy Group, Faculty of Pharmacy, University of Benin, Benin City, 300001 Nigeria.

\title{
Silencing of acetyl-CoA carboxylase- $\alpha$ gene in human gastric cancer cells inhibits proliferation via induction of apoptosis, autophagy and suppression of cell invasion
}

\author{
Chunsong $\mathrm{Yu}^{1}$, Xuehong $\mathrm{Wu}^{1}$, Bihua $\mathrm{Yao}^{1}$, Huaxing Tao ${ }^{2 *}$ \\ ${ }^{1}$ Clinical Laboratory, The First People's Hospital of Jiashan, ${ }^{2}$ Department of Infection, The First People's Hospital of Jiashan \\ County, Zhejiang Province 314100, China
}

*For correspondence: Email: HongMclaughlinbmh@yahoo.com; Tel: 0086-0573-84039637

\begin{abstract}
Purpose: To study the role and therapeutic potential of acetyl-CoA-carboxylase- $\alpha$ (ACC) in the management of gastric cancer.

Methods: Expression of ACC in gastric cancer cell lines was determined using quantitative real-time polymerase chain reaction ( $Q R T-P C R$ ). Lipofectamine 2000 reagent was used for transfection, while cell viability was determined by MTT assay. Apoptotic cell death was assayed with 4', 6-diamidino-2phenylindole (DAPI) and acridine orange/ethidium bromide (AO/EB) staining. The proportion of apoptotic cells was estimated with Annexin V/PI staining. Wound healing and Transwell assays were employed to monitor cell migration and invasion, while protein expression was determined using western blotting.

Results: The results showed that ACC was significantly enhanced in SNU-1 gastric cancer cells (4.2fold). Silencing of ACC in SNU-1 gastric cancer cells caused significant decrease in cell proliferation ( $p$ $<0.05$ ). Electron microscopy examination showed that $A C C$ silencing triggered autophagic cell death in SNU-1 cells, and increased expression of LC3 II. Results from DAPI and AO/EB assays demonstrated that ACC silencing also promoted apoptosis in SNU-1 gastric cancer cells. Annexin V/PI assay results revealed that apoptotic cell population increased from 2.7 to $13.8 \%$ due to ACC silencing $(p<0.05)$. Moreover, Bax expression increased, while Bcl-2 expression decreased upon ACC silencing. Transwell assay results indicate that ACC silencing caused marked decrease in the invasion of the SNU-1 cells and downregulation of the expressions of MMP-2 and MMP-9 $(p<0.05)$.

Conclusion: $A C C$ is likely to be an important therapeutic target for gastric cancer.
\end{abstract}

Keywords: Gastric cancer, Acetyl-CoA-carboxylase- $\alpha$, Apoptosis, Invasion, Autophagy

This is an Open Access article that uses a fund-ing model which does not charge readers or their institutions for access and distributed under the terms of the Creative Commons Attribution License (http://creativecommons.org/licenses/by/4.0) and the Budapest Open Access Initiative (http://www.budapestopenaccessinitiative.org/read), which permit unrestricted use, distribution, and reproduction in any medium, provided the original work is properly credited.

Tropical Journal of Pharmaceutical Research is indexed by Science Citation Index (SciSearch), Scopus, International Pharmaceutical Abstract, Chemical Abstracts, Embase, Index Copernicus, EBSCO, African Index Medicus, JournalSeek, Journal Citation Reports/Science Edition, Directory of Open Access Journals (DOAJ), African Journal Online, Bioline International, Open-J-Gate and Pharmacy Abstracts

\section{INTRODUCTION}

Accumulating evidence suggest that genes involved in long-chain fatty acid biosynthesis are significantly upregulated in tumor tissues [1].
Indeed, fatty acid synthase (FAS) has been shown to be involved in the development of tumors [2]. Similarly, acetyl-CoA-carboxylase- $\alpha$ (ACC) has been shown to be upregulated in breast and prostate cancers $[3,4]$. Therefore, it is 
believed that genes encoding enzymes involved in lipogenesis may act as important therapeutic targets for cancer prevention and treatment [5]. Although the role of ACC has been investigated in many cancer types, its role in gastric cancer is yet to be studied. This study was therefore designed to investigate the role and therapeutic implications of ACC in gastric cancer. Gastric cancer accounts for large percentage of cancerrelated mortalities annually, and it is one of the frequently diagnosed cancers. In 2002 alone, gastric cancer caused 650,000 deaths, while 900,000 new cases were diagnosed $[6,7]$. It has been reported that gastric cancer incidence varies with geographical zones, with the developing countries having comparatively higher incidence than developed countries $[8,9]$. Although recent reports showed considerable improvement in the five-year survival of gastric cancer patients, the five-year survival for other cancers is still poor [10]. The dearth of efficient chemotherapeutic drugs and therapeutic targets imposes hurdles in gastric cancer treatment [11]. This study was carried out to investigate the role and therapeutic potential of acetyl-CoAcarboxylase- $\alpha$ (ACC) in the management of gastric cancer.

\section{EXPERIMENTAL}

\section{Cell culture conditions}

The gastric cancer cell lines (AGS, SNU-1, SNU5 and KATOIII) and normal gastric cells (GES-1) were procured from Sun Yat-sen University Cancer Center (Guangzhou, China). RPMI- 1640 (Invitrogen) culture medium supplemented with $10 \%$ FBS was used for culturing the cell lines which were maintained in a humidified incubator with $9 \% \mathrm{CO}_{2}$ at $37^{\circ} \mathrm{C}$.

\section{Determination of ACC expression}

Total RNA was isolated using TRIzol (Invitrogen) reagent. This was followed by DNAse I treatment and cDNA synthesis using High-Capacity cDNA Archive $^{\mathrm{TM}}$ Kit in line with the manufacturer's protocol. With human GAPDH gene as internal control, RT-PCR based expression analysis was performed using SYBR Green method. The amplification conditions were $10 \mathrm{~min}$ initial denaturation at $95{ }^{\circ} \mathrm{C}$, followed by 40 cycles of $30 \mathrm{sec}$ denaturation at $95^{\circ} \mathrm{C}, 30 \mathrm{sec}$ of primer annealing at $58{ }^{\circ} \mathrm{C}$, and $20 \mathrm{sec}$ of extension at 72 ${ }^{\circ} \mathrm{C}$.

\section{Cell transfection}

Transfection of SNU-1 cancer cells was performed using Lipofectamine 2000 (Invitrogen) reagent following manufacturer's protocol. When $80 \%$ of cell confluence was attained posttransfection, the cells were PBS-washed, after which they were treated with $0.25 \%$ trypsin to obtain a homogenous cell suspension.

\section{Cell viability}

The proliferation of SNU-1 cells was assayed using 3-(4,5-dimethylthiazol-2-yl)-2,5-diphenyl tetrazolium bromide (MTT, Thermo Fisher Scientific). The cells were seeded in 96-well plate at a density of $1 \times 10^{6}$ cells/well. Then, $15 \mu$ l of MTT solution was added to each well. After $2 \mathrm{~h}$ of incubation at $37^{\circ} \mathrm{C}$, absorbance was read in a spectrophotometer at $500 \mathrm{~nm}$.

\section{DAPI and AO/EB staining assay}

The SNU-1 cells $\left(0.6 \times 10^{6}\right)$ were cultured in 6well plates for $24 \mathrm{~h}$ at $37{ }^{\circ} \mathrm{C}$. Subsequently, 25 $\mu \mathrm{L}$ of cell culture was put onto glass slides and stained with a $1 \mu \mathrm{L}$ of AO/EB or DAPI. The slides were covered with cover slips, and the cells were examined under fluorescence microscopy.

\section{Flow cytometric analysis of cell cycle}

The transfected SNU-1 cells were cultured at 37 ${ }^{\circ} \mathrm{C}$ for $24 \mathrm{~h}$ in a 6-well plate at a density of $2 \times 10^{5}$ cells/well. Thereafter, the SNU-1 cell suspension was centrifuged and pellets were washed in PBS buffer and fixed in $70 \%$ ethanol. Then, the cells were stained with propidium iodide $(\mathrm{PI})$ solution. The progression of cell cycle was examined using a flow cytometer, and the percentage of cells at each different cell cycle phase was determined.

\section{Transwell assay}

The transfected SNU-1 cells were plated at cellular density of $1 \times 10^{5}$ cells in the upper chamber of transwell plate with Matrigel coating. The cells were allowed to grow for $24 \mathrm{~h}$ at $37^{\circ} \mathrm{C}$ and $5 \% \mathrm{CO}_{2}$. Thereafter, cancer cells that invaded the lower chamber were fixed in $70 \%$ ethanol and stained with $0.1 \%$ crystal violet solution. The invasive cells were visualized under 100x magnification light microscope and photographed.

\section{Western blotting}

Total proteins were isolated from SNU-1 cells with RIPA lysis and extraction buffer (Thermo Fisher Scientific). The proteins were quantified using Bradford's reagent. Using electrophoretic method, $40 \mu \mathrm{g}$ of protein was separated on $12 \%$ SDS-PAGE, and the gel contents were then 
transferred to the PVDF membranes through blotting method. The membranes were incubated with primary antibodies, followed by incubation with secondary antibodies at $4{ }^{\circ} \mathrm{C}$ in the dark. The relative protein expression was determined using chemiluminescent, with human actin gene as normalization control.

\section{Statistical analysis}

Data are expressed as mean \pm SD. Graphpad Prism 7 software was used to perform $t$-test. Values of $p \leq 0.05$ were taken as indicative of statistically significant differences.

\section{RESULTS}

\section{ACC was upregulated in gastric cancer cells}

The transcript levels of ACC were assayed in different gastric cancer cells using qRT-PCR. Acetyl-CoA carboxylase (ACC) was significantly overexpressed in the gastric cancer cells, relative to normal GES-1 cells (Figure 1A). The ACC expression was about 4.2 times higher in the gastric cancer cells, with SNU-1 having the highest expression of ACC among the cell lines.

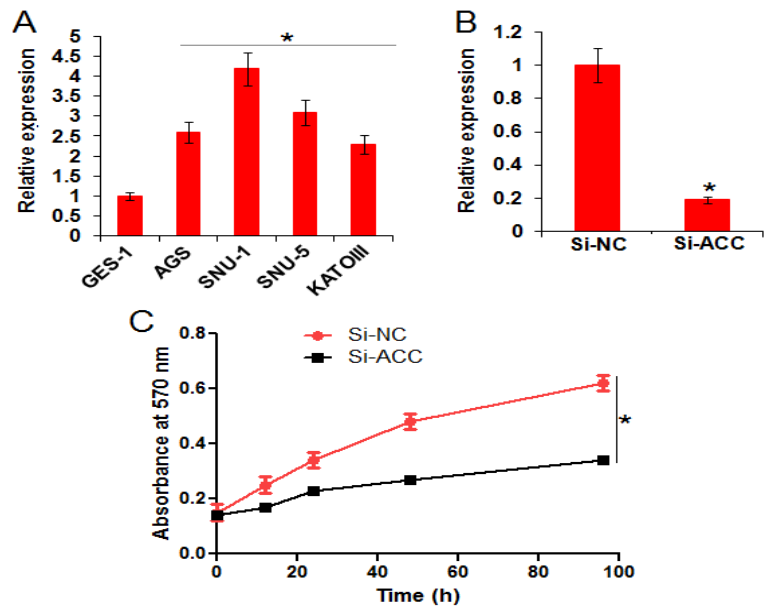

Figure 1: (A) Expression of ACC in different gastric cancer cell lines and normal GES-1 cells, as determined using qRT-PCR. (B) Relative expression of ACC in si-NC or si-ACC-transfected SNU-1 cells. (C) MTT assay showing the proliferation of the si-NC or si-ACC transfected SNU-1 cells. The experiments were performed in triplicate, and the results are expressed as mean \pm SD $\left({ }^{*} p<0.05\right)$

\section{Suppression of ACC inhibited proliferation of SNU-1 gastric cancer cells}

To assess the impact of ACC silencing on the proliferation of SNU-1 gastric cancer cells, siACC transfected SNU-1 cells were subjected to MTT assay. Silencing of ACC was validated with
qRT-PCR which showed 5 -fold reduction in ACC expression (Figure $1 \mathrm{~B}$ ). Following this, cell viability was determined at different time intervals, and it was revealed that ACC suppression resulted in significant decline in the proliferation of SNU-1 cells (Figure $1 \mathrm{C}$ ).

\section{Suppression of ACC induced autophagy in SNU-1 cells}

Electron microscopic analysis of si-NC and siACC-transfected SNU-1 cells revealed that ACC silencing in SNU-1 cells resulted in the development of autophagosomes, which was indicative of autophagy (Figure 2 A). The autophagy was confirmed using western blot analysis of si-NC and si-ACC-transfected SNU-1 cells. It was found that silencing of ACC in SNU1 cells resulted in significant increase in the expression of LC3-II, thereby confirming autophagic cell death of SNU-1 cells (Figure 2B).

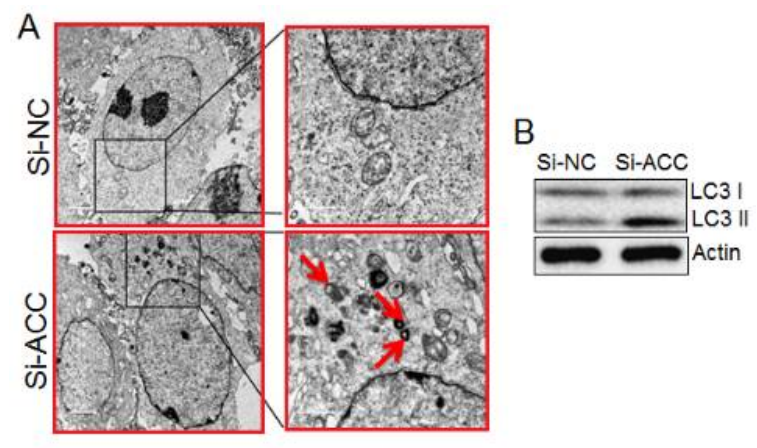

Figure 2: (A) Electron microscopic analysis showing induction of autophagy in si-ACC transfected SNU-1 cells. (B) Effect of si-NC or si-ACC transfection on the protein expressions of the LC3-I and LC3-II. The experiments were performed in triplicate

\section{Suppression of ACC induced apoptosis in SNU-1 cells}

To unveil if ACC silencing also induced apoptosis, SNU-1 cells were transfected with siNC or si-ACC. This was followed by staining of cells separately with AO/EB and DAPI. These assays showed that ACC silencing induced nuclear fragmentation in the SNU-1 cells, indicating apoptosis (Figures $3 \mathrm{~A}$ and $\mathrm{B}$ ). Next, Annexin V/PI staining was performed to determine the percentage of apoptotic SNU-1 cells. It was found that in si-NC-transfected SNU1 cells, the percentage of apoptotic cells was 2.7, relative to $13.8 \%$ in si-ACC-transfected SNU-1 cells (Figure $4 \mathrm{~A}$ ). Furthermore, ACC silencing caused increase in the expression of Bax, and decrease in the expression of $\mathrm{Bcl}-2$, which further confirmed apoptosis (Figure $4 \mathrm{~B}$ ). 

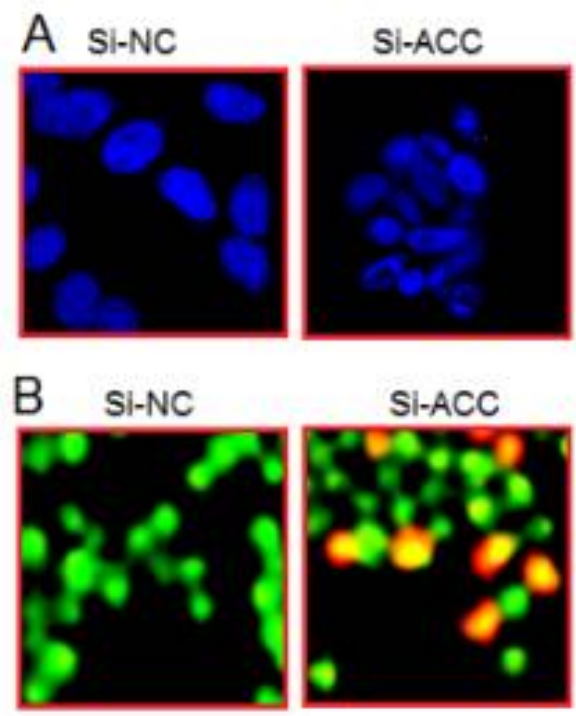

Figure 3: (A) DAPI staining, and (B) AO/EB staining showing the effects ACC silencing on SNU-1 cells. The experiments were performed in triplicate
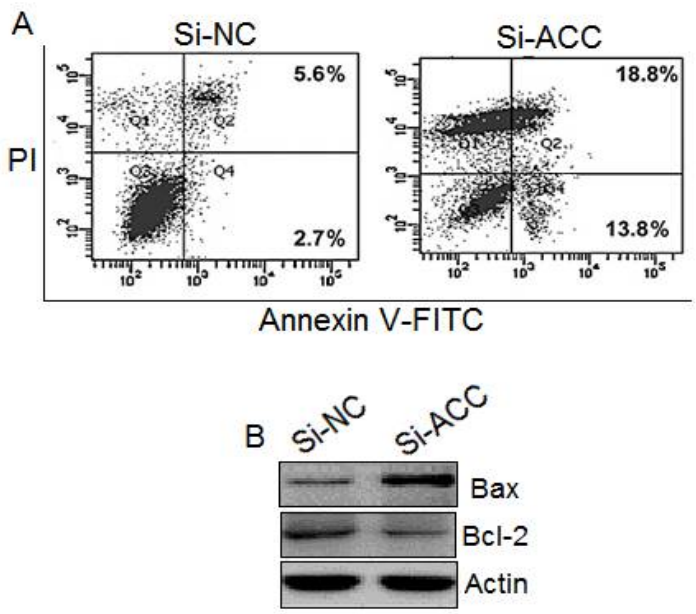

Figure 4: (A) Effect of si-NC and Si-ACC transfection on percentage of apoptosis cell in SNU-1 cells as depicted with Annexin V/PI staining (B) Western blotting showing the effects of si-NC or si-ACC on the expressions of $\mathrm{Bax}$ and $\mathrm{Bcl}-2$ proteins. The experiments were performed in triplicate

\section{Suppression of ACC inhibited the invasion of gastric cancer cells}

The impact of ACC silencing on the invasion of the SNU-1 cells was studied using transwell assay. It was revealed that ACC silencing caused significant decline in the invasion of the SNU-1 cells (Figure $5 \mathrm{~A}$ ). The invasion of the SNU-1 cells was decreased by $67 \%$, which was also concomitant with decrease in the expressions of MMP-2 and MMP-9, as confirmed with results from western blot analysis (Figure 5 B).

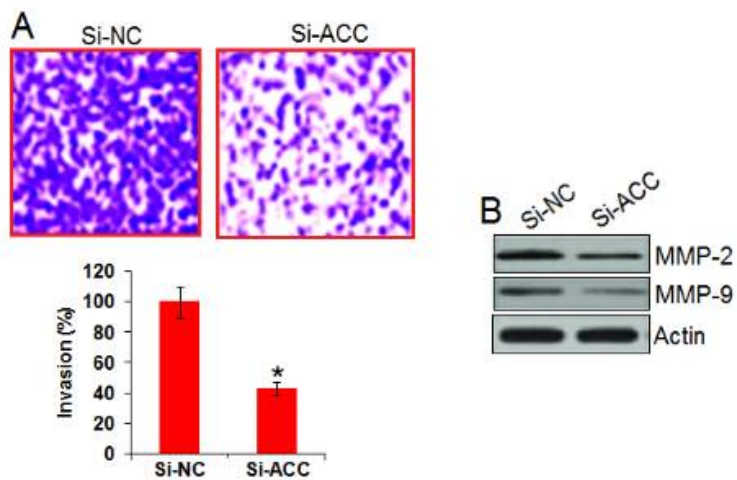

Figure 5: (A) Effects of si-NC and Si-ACC transfections on the migration of $\mathrm{SNU}-1$ cells; (B) effects of si-NC and Si-ACC transfections on the expressions of MMP-2 and MMP-9. The experiments were performed in triplicate, and the results are expressed as mean $\pm \mathrm{SD}\left({ }^{*} p<0.05\right)$

\section{DISCUSSION}

Although there have been recent improvements in overall survival of gastric cancer, the disease still causes enormous mortality throughout the world [12]. For instance, half of the cancer cases diagnosed in East Asian countries are gastric cancers [10]. The currently used chemotherapy for gastric cancer has negative effects on the health of the patients, and efficient therapeutic targets are lacking [11]. This study was undertaken to investigate the therapeutic implications of ACC in in gastric cancer. It was found that the expression of ACC was highly enhanced in the gastric cancer cells used in the present study. In order to decipher its role, the expression of ACC was silenced in SNU-1 gastric cancer cells, and it was found that ACC silencing caused significant decrease in the viability of the SNU-1 cells. These results are in agreement with the findings from previous investigations wherein suppression of ACC was shown to inhibit prostate cancer cell proliferation via induction of apoptosis [13].

Autophagy is an important defensive mechanism that allows an organism to eliminate harmful and defective cells, and it helps to maintain tissue homeostasis [14]. In this study, it was found that silencing of ACC caused autophagic death of the SNU-1 gastric cancer cells, as well as increases in the expression of LC3 II. In previous studies, silencing of ACC caused apoptosis in human cancer cells [15]. Hence, several assays were carried out which revealed that ACC silencing triggered apoptosis in the SNU-1 cells. The induction of apoptosis was also accompanied by the alterations in the levels of apoptosis biomarker proteins. The expression of Bax was significantly increased, while Bcl-2 expression 
was significantly decreased. Together, these results suggest that ACC may act as a therapeutic target for in the treatment of gastric cancer. Invasion of the cancer cells to the neighbouring organs is one of the first steps in the metastasis of cancers [16]. In the present study, it was found that ACC silencing resulted in significant decline in the invasion of the gastric cancer cells.

\section{CONCLUSION}

The findings of the present study indicate that ACC is upregulates in human gastric cancer cells. Silencing of ACC inhibits the proliferation of the gastric cancer cells via induction of apoptosis and autophagy. Moreover, ACC silencing inhibits the invasion of the gastric cancer cells, indicating the therapeutic implications of ACC in gastric cancer.

\section{DECLARATIONS}

\section{Acknowledgement}

The corresponding author acknowledges Huaxing Tao Department of Infection, The First People's Hospital of Jiashan County, Zhejiang Province 314100 , China for providing some of the facilities used for this study.

\section{Conflict of interest}

No conflict of interest is associated with this work.

\section{Contribution of authors}

The authors declare that this work was done by the authors named in this article and all liabilities pertaining to claims relating to the content of this article will be borne by them. This work is performed by Chunsong $\mathrm{Yu}$ and Xuehong $\mathrm{Wu}$. Bihua Yao collected the data. All the experiments are supervised by Huaxing Tao.

\section{Open Access}

This is an Open Access article that uses a funding model which does not charge readers or their institutions for access and distributed under the terms of the Creative Commons Attribution License (http://creativecommons.org/licenses/by/ 4.0) and the Budapest Open Access Initiative (http://www.budapestopenaccessinitiative.org/rea d), which permit unrestricted use, distribution, and reproduction in any medium, provided the original work is properly credited.

\section{REFERENCES}

1. Kuhajda FP. Fatty-acid synthase and human cancer: new perspectives on its role in tumor biology. Nutrition 2000;16: 202-208.

2. Baron A, Migita T, Tang D, Loda M. Fatty acid synthase: a metabolic oncogene in prostate cancer? J Cell Biochem 2004; 91: 47-53.

3. Swinnen JV, Vanderhoydonc F, Elgamal AA, Eelen M, Vercaeren I, Joniau S, Van Poppel H, Baert $L$, Goossens K, Heyns $W$, Verhoeven $G$. Selective activation of the fatty acid synthesis pathway in human prostate cancer. Int J Cancer 2000; 88: 176-179.

4. Milgraum LZ, Witters LA, Pasternack GR, Kuhajda FP. Enzymes of the fatty acid synthesis pathway are highly expressed in in situ breast carcinoma. Clin Cancer Res 1997; 3: 2115-2120.

5. Kusakabe T, Nashimoto A, Honma K, Suzuki T. Fatty acid synthase is highly expressed in carcinoma, adenoma and in regenerative epithelium and intestinal metaplasia of the stomach. Histopathol 2002; 40: 71-79.

6. Venerito $M$, Vasapolli $R$, Rokkas $T$, Malfertheiner $P$. Gastric cancer: epidemiology, prevention, and therapy. Helicobacter 2018; 23: e12518.

7. Sitarz $R$, Skierucha $M$, Mielko J, Offerhaus GJ, Maciejewski $R$, Polkowski WP. Gastric cancer: epidemiology, prevention, classification, and treatment. Cancer Mang Res 2018; 10: 239.

8. Rugge M, Fassan M, Graham DY. Epidemiology of gastric cancer. In Gastric Cancer. Springer, Cham; 2015; pp 23-34.

9. Karimi P, Islami F, Anandasabapathy S, Freedman ND, Kamangar F. Gastric cancer: descriptive epidemiology, risk factors, screening, and prevention. Cancer EpidemiolPrevn Biomark2014: cebp-1057

10. Fock KM. The epidemiology and prevention of gastric cancer. Aliment Pharmacol Ther . 2014; 40: 250-260.

11. Smyth EC, Verheij $M$, Allum $W$, Cunningham $D$, Cervantes A, Arnold D. Gastric cancer: ESMO Clinical Practice Guidelines for diagnosis, treatment and followup. Annals of Oncology 2016; 27: v38-49.

12. Shen L, Li J, Xu J, Pan H, Dai G, Qin S, Wang L, Wang $J$, Yang Z, Shu Y, Xu R. Bevacizumab plus capecitabine and cisplatin in Chinese patients with inoperable locally advanced or metastatic gastric or gastroesophageal junction cancer: randomized, double-blind, phase III study (AVATAR study). Gastric Cancer 2015;18: 168176.

13. Brusselmans K, De Schrijver E, Verhoeven G, Swinnen JV. RNA Interference-Mediated Silencing of the AcetylCoA-Carboxylase-a Gene Induces Growth Inhibition and Apoptosis of Prostate Cancer Cells. Cancer Res. 2005; 65: 6719-6725.

14. Suzuki R, Kang YA, Li X, Roife D, Zhang R, Fleming JB. Genistein potentiates the antitumor effect of 5Fluorouracil by inducing apoptosis and autophagy in human pancreatic cancer cells. Anticancer Res 2014; 34: 4685-4692.

Trop J Pharm Res, October 2019; 18(10):2029 
15. Wang $C$, Xu C, Sun M, Luo D, Liao DF, Cao D. AcetylCoA carboxylase- $\alpha$ inhibitor TOFA induces human cancer cell apoptosis. Bioch Biophyl Res Comm2009; 385: 302-306.
16. Luo W, Song Z, Sun H, Liang J, Zhao S. Bergamottin, a natural furanocoumarin abundantly present in grapefruit juice, suppresses the invasiveness of human glioma cells via inactivation of Rac1 signaling. Oncol Lett 2018;15: 3259-3266. 